\title{
Green turtle somatic growth dynamics: distributional regression reveals effects of differential emigration
}

\author{
Karen A. Bjorndal ${ }^{1, *}$, Alan B. Bolten ${ }^{1}$, Milani Chaloupka ${ }^{2}$ \\ ${ }^{1}$ Archie Carr Center for Sea Turtle Research and Department of Biology, University of Florida, Gainesville, FL 32611, USA \\ ${ }^{2}$ Ecological Modelling Services Pty Ltd, University of Queensland, St Lucia, QLD 4067, Australia
}

\begin{abstract}
Because somatic growth is an integrated response to variables on individual, population and ecosystem levels, growth rates have been used as indicators of change in a wide range of demographic and environmental variables. Models of sea turtle growth that relate changes in productivity to environmental changes have all focused on the mean or expected growth rate. We used distributional regression analysis for the first time in sea turtle growth studies to evaluate both the mean and variance of the growth response as a function of covariates. We analyzed a 39 yr (1979-2017) data set with 1176 growth increments for 727 green turtles Chelonia mydas from a capture-mark-recapture study in the southern Bahamas. The distributional regression model had an improved fit to the growth data in comparison to the mean-response-only model. By testing predictions based on inspection of variance plots, we reveal novel insights on the importance of differential growth rates as cues for emigration. Variance in growth rates decreases with increasing body size and increasing population density because turtles that grow slowly at small sizes or at high densities exhibit differential emigration. Drivers of differential emigration have received little attention in demographic studies of sea turtle foraging aggregations and will be more important as sea turtle populations recover and population densities on foraging grounds increase. Future conservation and management of increasing green turtle populations depend on improved understanding of resource use, sustainability of grazing, and cues for emigration. Distributional regression is a powerful analytical approach for these studies.
\end{abstract}

KEY WORDS: Developmental migrations $\cdot$ GAMMLSS growth model $\cdot$ Sea turtle

\section{INTRODUCTION}

Somatic growth dynamics are an integrated response to a wide range of parameters at the levels of the individual (e.g. nutrition, health, differential investment in growth and reproduction), population (e.g. density, demography), and ecosystem (e.g. resource availability, climate). Changes in any of these parameters and/or interactions among parameters can have direct or indirect effects on somatic growth. Because growth rates can be sensitive indicators of changes at these 3 levels, understanding the sources of variation in growth rates is critical to improve their

\footnotetext{
*Corresponding author: bjorndal@ufl.edu
}

use as indicators of population, demographic, and environmental changes.

Growth rates of sea turtles are excellent models for demographic and environmental indicators because sea turtles are long-lived, highly migratory megaconsumers. Green turtles Chelonia mydas, loggerheads Caretta caretta, and hawksbills Eretmochelys imbricata spend decades in neritic habitats growing to sexual maturity. During this immature period, individuals may move 100 s to 1000 s of $\mathrm{km}$ among foraging grounds in a series of developmental migrations (Musick \& Limpus 1997, Meylan et al. 2011). Growth rates of these 3 species measured over decades

๑ The authors 2019. Open Access under Creative Commons by Attribution Licence. Use, distribution and reproduction are unrestricted. Authors and original publication must be credited. 
revealed the widespread effects of an ecological regime shift on sea turtles from 3 different trophic levels in the West Atlantic region beginning in the late 1990s (Bjorndal et al. 2017).

Many studies of sea turtle somatic growth have been conducted based on a number of analytical approaches (Chaloupka \& Musick 1997, Avens \& Snover 2013). Sea turtle growth rates are characterized by high variation, much of which remains unexplained (Balazs \& Chaloupka 2004, Braun-McNeill et al. 2008, Patrício et al. 2014, Colman et al. 2015, Bjorndal et al. 2017). This heterogeneity might be a function of important predictors or covariates which could provide further insights into sea turtle growth dynamics. Understanding the drivers of variation in growth rates is ever more critical as sea turtle populations recover, increasing density-dependent effects; as marine resources upon which sea turtles depend are degraded; and as climate change affects ecosystem processes. As models are improved, sources of this variation are better understood and predictions of the effects of climate change, emerging diseases, and population abundance, among other factors, are enhanced.

All previous sea turtle growth models of which we are aware have focused on the mean or expected growth rate. This has been a common mathematical approach - the mean field theory-in ecological and evolutionary sciences in which the behavior of the mean is modeled without incorporating variance (review in Violle et al. 2012). In recent years, distributional regression or 'going beyond the mean' (Kneib 2013, Stasinopoulos et al. 2018) —in which modeling is not restricted to the mean of the response variable, but extended to other summary parameters of the response distribution (e.g. variance, skewness, and kurtosis) - has received greater emphasis (DeCarlo et al. 2015, Gilman et al. 2016, Silbersdorff et al. 2018). This approach models both the response mean and variance as a function of covariates and can yield important new observations, as demonstrated in recent papers. For example, Campbell et al. (2012) found that population dynamics of Eurasian beavers Castor fiber were more influenced by climate components describing variance than by those describing mean values. For polar bears Ursus maritimus, Trotter et al. (2013) concluded that including variance sensitivities with mean stochastic growth rate and its sensitivities yielded a substantially more complete understanding of population dynamics.

Given the number of biotic and abiotic factors that can affect growth in individual turtles, this modeling approach should yield important insights into growth dynamics in foraging aggregations of sea turtles. We used distributional regression modeling to evaluate green turtle somatic growth dynamics for both the mean and variance of the growth response as a function of covariates. We analyzed a 39 yr (1979-2017) data set from a capture-mark-recapture study of green turtles in the southern Bahamas. We illustrate how distributional regression can improve our understanding of variation in growth dynamics in sea turtles and thus improve the use of growth rates to interpret population, demographic, and ecological changes. Specifically, we addressed what stimulates sea turtles to emigrate from foraging grounds in response to changes in body size and population density. Cues that initiate emigration during developmental migrations are key for understanding these movement patterns and resource use, particularly where green turtle populations are increasing (Bjorndal et al. 2000, Meylan et al. 2011, Christianen et al. 2014, Lacey et al. 2014).

\section{MATERIALS AND METHODS}

\subsection{Study site, data collection and preparation of data set}

This study is part of a long-term study of the biology of immature green turtles in Union Creek Reserve $\left(\mathrm{UCR}_{i} 21.178^{\circ} \mathrm{N}, 73.578^{\circ} \mathrm{W}\right)$ on the north coast of Great Inagua, the southernmost island in The Bahamas. In The Bahamas, the term 'creek' is applied to saltwater bays, not freshwater streams, as in some other countries. UCR is part of the Bahamas Protected Areas system managed by the Bahamas National Trust (BNT), and green turtles are protected by legislation that is well-enforced by BNT wardens. UCR is $\sim 20 \mathrm{~km}^{2}$ in area, is surrounded by and interspersed with mangroves, and has meadows of seagrass Thalassia testudinum, the primary diet plant of green turtles in the Greater Caribbean (Bjorndal 1997). UCR can be divided into 2 areas: the Upper Sound and the Lower Sound. The Lower Sound is characterized by shallower water and Thalassia meadows that show more signs of stress (brown leaf tips and narrower leaf blades) compared to the Upper Sound. The disease fibropapillomatosis that may affect growth rates in green turtles (Chaloupka \& Balazs 2005) has not been observed in UCR.

Immature green turtles enter UCR and then emigrate within a few years to other habitats in deeper waters throughout the Greater Caribbean prior to the onset of sexual maturity. Green turtle aggregations in UCR are mixed stocks derived from several rook- 
eries in the Atlantic, based on analyses of mtDNA sequences (Bjorndal \& Bolten 2008).

Each year during a single survey interval, green turtles were caught throughout the study area by diving from the bow of a motorboat following a brief chase. We used the number of turtles captured each year (Fig. S1 in the Supplement at www.int-res.com/ articles/suppl/m616p185_supp.pdf) as an index of relative density of turtles in UCR as in Bjorndal et al. (2000) and later supported by Bjorndal et al. (2005). We are confident that the number of turtles captured during each survey period is a reliable estimate of relative density because of the consistency of annual capture effort. Throughout our study, we only used one capture method, only 3 people ran the capture boat, and only 5 people (including 2 of the boat operators) dived on turtles. Number of capture days varied between 5 and 10 among years to account for variation in weather conditions, and was not related to number of turtles captured (Spearman correlation, rho $=0.225, p=0.196$ ). In addition, based on capturemark-recapture analyses for years 1979 through 2001 except 1981, 1995, 1999 when no field studies were undertaken (Bjorndal et al. 2005), relative mean density index is closely related to a Horvitz-Thompson type estimate of abundance (linear regression, $\mathrm{p}<$ $0.0001, \mathrm{R}^{2}=0.804, \mathrm{n}=20$; Fig. S2).

Turtles were tagged with flipper tags bearing an identification number. Straight carapace length (SCL, $\pm 0.1 \mathrm{~cm}$ ) was measured with anthropometer calipers (GPM model 101) from the anterior midpoint of the nuchal scute to the posterior tip of the longer of the pair of posterior marginal scutes (Bolten 1999). All measurements were made by A.B.B. and recorded by K.A.B. The precision of SCL, determined as mean discrepancy between repeated measurements, was $0.046 \mathrm{~cm}$ (Bjorndal \& Bolten 1988). No negative growth rates were observed. Sex of 111 turtles captured in 1988 was identified by collecting blood samples and measuring circulating levels of testosterone (Bolten et al. 1992).

We used a mixed longitudinal sampling design (sampling with partial replacement). Of the $727 \mathrm{in}$ dividual turtles with growth increments, $303(42 \%)$ were recaptured more than once. Absolute growth rates were derived from the capture-mark-recapture profiles for individual turtles captured from 1979 through 2017. For each growth increment, the following covariates were included: turtle ID, mean SCL (mean of initial and recapture SCL, in $\mathrm{cm}$ ), mean year (year of mean date of initial and recapture date), mean density index (mean of initial and recapture density index), duration between capture and recap- ture in years (number of days elapsed between initial capture and recapture divided by $365.25 \mathrm{~d}$ ), location (initial capture in Lower Sound or in Upper Sound), and sex (female, male, unknown).

To avoid the bias introduced by short durations between capture and recapture, we used the standard $330 \mathrm{~d}$ minimum cutoff that has been used for many years in sea turtle studies (Chaloupka \& Limpus 1997, Bjorndal et al. 2017). Successive growth increments for individual turtles below the $330 \mathrm{~d}$ limit were combined to exceed the minimum duration when possible.

All applicable international, national, and/or institutional guidelines for the care and use of animals were followed. All procedures were performed in compliance with the Institutional Animal Care and Use Committee at the University of Florida.

\subsection{Statistical modeling approach}

We used a generalized additive mixed model for location, scale and shape (GAMMLSS; Stasinopoulos \& Rigby 2007), which is a form of structured additive distributional regression (Klein et al. 2015). The GAMMLSS approach allows the simultaneous modeling of (1) the mean (or expected) somatic growth rate response as a function of covariates and (2) the variance or dispersion of the same response, also as a function of informative covariates. We used Bayesian inference implemented with the Stan computation engine (Stan Development Team 2016) with NUTS sampling (Carpenter et al. 2017) via the 'brms' package for R (Bürkner 2017) to fit the GAMMLSS model structure.

The GAMMLSS regression models comprised (1) an identity link, (2) Student's $t$ model likelihood to minimize outlier effects on parameter estimates, and (3) thin plate regression spline smooths (Wood 2006) to model any nonlinear functional form between mean somatic growth rates and the covariates described above. The somatic growth rate variance was jointly modeled as a function of covariates. We also included turtle ID as a random effect (random intercepts only) to account for any turtle-specific heterogeneity due to the variable number of growth rate measurements recorded for each turtle.

The GAMMLSS models implemented in the Bayesian framework used weakly informative regularizing priors (Gelman et al. 2008, Park \& Casella 2008) with posterior samples sourced from 4 chains and 25000 iterations after a warmup of 2500 iterations. Bayesian GAMMLSS regression model fit was dis- 
played using the 'ggplot2' package for R (Wickham 2016) and then evaluated using graphical posterior predictive checking procedures (Gelman \& Hill 2007, Gelman et al. 2014) via the 'bayesplot' package for $\mathrm{R}$ (Gabry 2016).

To determine if accounting explicitly for variance in growth rates improved the fit to the data and model inference about the mean growth rate dynamics, we dropped the variance covariates from our GAMMLSS model to create a Bayesian GAMM mean-responseonly model. We used leave-one-out cross-validation (LOOIC) and $K$-fold cross-validation (KFOLDIC) to compare the GAMMLSS fits to the simpler GAMM model (fitted using the 'gamm4' package for $\mathrm{R}_{i}$ Wood \& Scheipl 2014). LOOIC is an approximate method and is known to be prone to false positives when applied to more complex hierarchical models (Vehtari et al. 2017, Gabry et al. 2019). So in addition to LOOIC, we used the computationally more intensive but more reliable KFOLDIC (10-fold cross-validation with 4 chains) to assess whether the same conclusions were drawn about model comparison based on the approximate LOOIC metric (Vehtari et al. 2017, Gabry et al. 2019). Finally, the selected model was thoroughly evaluated using a suite of posterior predictive check tests, which is the most informative means for evaluating Bayesian model fit (Vehtari et al. 2017, Gabry et al. 2019). All analyses were conducted in R version 3.4.2 (R Core Team 2017).

\subsection{Assessing causes of shifts in variance}

To evaluate the shifts in variance that were revealed by the GAMMLSS analyses, we assessed 3 predictions, described in Table 2 and Sections 3.4, 3.5 and 3.6. To determine if turtles that emigrated at different sizes were growing at different rates before emigration, we identified departure size (= SCL at last sighting) for all recaptured green turtles last seen in 2014 or before (Fig. S3). We are confident that turtles left soon after the last capture because the majority $(80.3 \%)$ of all recapture intervals was about 1 yr (Fig. S4). We can also be confident that all turtles captured in 2014 or before emigrated by the end of our study (2017) because $98.8 \%$ of all recapture intervals were 3 yr or less (Fig. S4). Annual survival probability of green turtles in UCR is high $(0.891$; Bjorndal et al. 2003), so green turtles that are no longer in the study area have usually emigrated, not died.

\section{RESULTS AND DISCUSSION}

\subsection{GAMMLSS model}

Our final data set had 1176 growth increments for 727 individual green turtles captured from 1979 through 2017. The number of growth increments for individual turtles varied from 1 to 9 with a mean $( \pm \mathrm{SD})$ of $1.6 \pm 0.9$. Growth rates from all growth increments varied from 0.1 to $11.0 \mathrm{~cm} \mathrm{yr}^{-1}$ with a mean of $4.4 \pm 2.0 \mathrm{~cm} \mathrm{yr}^{-1}$. SCL values from all turtle captures $(\mathrm{n}=2689$; Fig. 1a) varied from 25.3 to $84.3 \mathrm{~cm}$, and mean SCL values for all growth increments $(\mathrm{n}=$ 1176; Fig. 1b) ranged from 30.2 to $82.1 \mathrm{~cm}$.

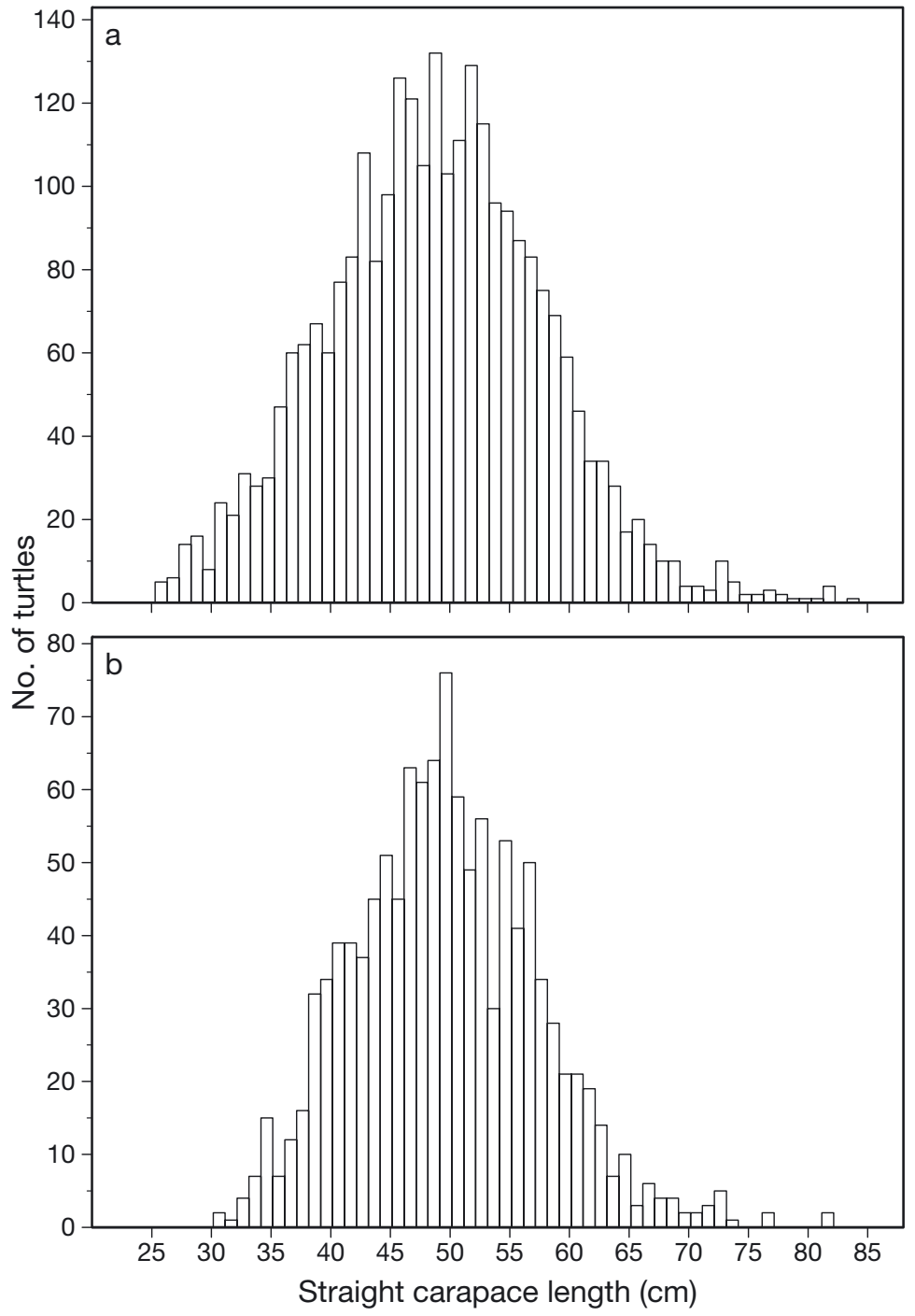

Fig. 1. Size distribution (straight carapace length [SCL] notch to tip in $\mathrm{cm})$ of (a) green turtle captures $(\mathrm{n}=2689)$ in Union Creek, Great Inagua, The Bahamas, from 1979 through 2017 and (b) mean SCL for growth increments $(n=1176)$. Measurements of individual turtles caught in successive years are included in (a) 
We tested a series of models with different combinations of covariates for both the mean response and the variance component. The best model had 6 fixed effect covariates for the mean growth response component (mean SCL, mean year, mean density index, duration, location, and sex) and 1 random effect (individual turtle). For the variance component, the best model had 3 covariates: mean SCL, mean year, and mean density index (Table 1). The model statement is:

brm(bf(gr.scl s(scl.mean)+s(mean.year,k=3)

$+\mathrm{s}$ (duration, $\mathrm{k}=3$ )

+s(density.mean, $\mathrm{k}=3$ )+location+sex+(1ITurtle), sigma $\sim$ s(scl.mean) $+\mathrm{s}($ mean.year $)+\mathrm{s}($ density.mean $)$, family=student $($ link='identity' $)$.

Table 1. Green turtle growth dynamics model results for fixed continuous effects and random effect. All parameters are significant (Bayesian 95\% credible interval does not include zero)

\begin{tabular}{|lccc|}
\hline Parameters & Estimate & SD & $\begin{array}{c}95 \% \text { Credible } \\
\text { interval }\end{array}$ \\
\hline $\begin{array}{l}\text { Fixed effects mean terms } \\
\text { Straight carapace length }\end{array}$ & 1.28 & 1.03 & $0.10-4.13$ \\
Year & 6.48 & 6.34 & $0.84-23.13$ \\
Relative density index & 4.72 & 5.78 & $0.13-19.89$ \\
$\begin{array}{l}\text { Duration } \\
\text { Fixed effects variance terms }\end{array}$ & 7.60 & 7.29 & $0.49-25.88$ \\
$\begin{array}{l}\text { Straight carapace length } \\
\text { Year }\end{array}$ & 1.08 & 0.87 & $0.07-3.29$ \\
$\begin{array}{l}\text { Relative density index } \\
\text { Random effect }\end{array}$ & 1.25 & 1.11 & $0.19-4.35$ \\
Individual turtles & 2.10 & 1.08 & $0.75-4.78$ \\
\hline
\end{tabular}

This model explains $69.9 \%$ of the model deviance (Bayesian $\mathrm{R}^{2}$; Gelman et al. 2017) and is a good fit to the data based on graphical posterior predictive checking procedures (Fig. S5). The convergence diagnostics of effective posterior sample size (921 to 90000 ) and the Gelman-Rubin statistic (Rhat $=1.00$ for all covariates) indicated convergence of the model (Gelman \& Hill 2007).

The distributional regression model (GAMMLSS) that accounts for growth variability had a substantially improved fit to the data compared to the meanresponse-only model (GAMMLSS LOOIC $=3970.38$, GAMM LOOIC $=4018.45$; GAMMLSS KFOLDIC $=$ 3980.20, GAMM KFOLDIC $=4016.75)$. There were no differences in the significance of the covariates between the 2 models. The better fit indicates the advantage of modeling both the mean and variance of the response distribution. More important, are the new insights that can be gained from this approach, as discussed below (Table 2 contains summary and statistical test results).

We only present the results of the distributional regression model (Figs. 2 \& 3, Table 1). Graphical results for mean responses (Figs. 2a,c,e \& 3a,b) are plotted with the original response scale $\left(\mathrm{cm} \mathrm{SCL} \mathrm{yr}^{-1}\right)$ on the $y$-axis to facilitate evaluation of covariate effects. Graphical results for variance responses (Fig. 2b,d,f) are plotted on a centered smoothed GAMMLSS function scale to allow direct comparisons of effect strength among covariates. Rug plots above the $x$-axes allow rapid assessment of relative sample size distribution for the continuous covariates.

Table 2. Summary of predictions regarding green turtle growth dynamics and emigration, tested based on results of distributional regression analyses. See Sections 3.4, 3.5 and 3.6 for discussion of predictions and results. GR: growth rate; SCL: straight carapace length; NS: not significant

\begin{tabular}{|c|c|c|c|}
\hline Model results & Predictions & Test and statistical results & Conclusions \\
\hline $\begin{array}{l}\text { Variance of GR de- } \\
\text { creases with increas- } \\
\text { ing SCL (Fig. 2b) }\end{array}$ & $\begin{array}{l}\text { Lower variance in larger turtles is } \\
\text { due to turtles that emigrate at } \\
\text { smaller sizes not being evenly } \\
\text { distributed along the growth rate } \\
\text { continuum }\end{array}$ & $\begin{array}{l}\text { Turtles that emigrate at smaller sizes }(<55 \mathrm{~cm}) \\
\text { grow significantly more slowly between } 31 \text { and } \\
54 \mathrm{~cm} \text { SCL than do turtles that leave at larger } \\
\text { sizes }(>55 \mathrm{~cm}) \\
\text { Mean } \pm \text { SE GR: small } 4.9 \pm 0.1 \text {; large } 5.3 \pm 0.1 \\
\text { Significant: } t \text {-test, } t=-2.993, \mathrm{df}=544.3, \mathrm{p}=0.003\end{array}$ & $\begin{array}{l}\text { Prediction } \\
\text { supported }\end{array}$ \\
\hline \multirow[t]{2}{*}{$\begin{array}{l}\text { Variance of GR de- } \\
\text { creases with } \\
\text { increasing relative } \\
\text { density index }{ }^{\text {a }} \text { (Fig. 2f) }\end{array}$} & $\begin{array}{l}\text { As densities increase, larger turtles } \\
\text { limit smaller turtles to lower } \\
\text { quality foraging habitats, reducing } \\
\text { variance in small turtles }\end{array}$ & $\begin{array}{l}\text { Variance of small turtles decreases with } \\
\text { increasing density } \\
\text { Variance of GR: low density } 3.33 ; \\
\text { high density } 3.37 \\
\text { NS: } F \text {-test, } F=1.011 ; \text { df }=175,155 ; \mathrm{p}>0.05\end{array}$ & $\begin{array}{l}\text { Prediction not } \\
\text { supported }\end{array}$ \\
\hline & $\begin{array}{l}\text { Differential emigration in larger } \\
\text { turtles: slower growing turtles } \\
\text { emigrate sooner }\end{array}$ & $\begin{array}{l}\text { For large turtles, mean GR stays the same and } \\
\text { variance decreases with increased density } \\
\text { Mean GR } \pm \text { SE: lower density } 3.5 \pm 0.1 ; \\
\text { higher density } 3.2 \pm 0.1 \\
\text { NS: } t \text {-test, } t=1.984, \text { df }=302.7, \mathrm{p}>0.05 \\
\text { Variances declined: low density } 3.08 ; \\
\text { high density } 1.24 \\
F \text {-test, } F=2.485 ; \text { df }=192,114 ; \mathrm{p}<0.0001\end{array}$ & $\begin{array}{l}\text { Prediction } \\
\text { supported }\end{array}$ \\
\hline
\end{tabular}



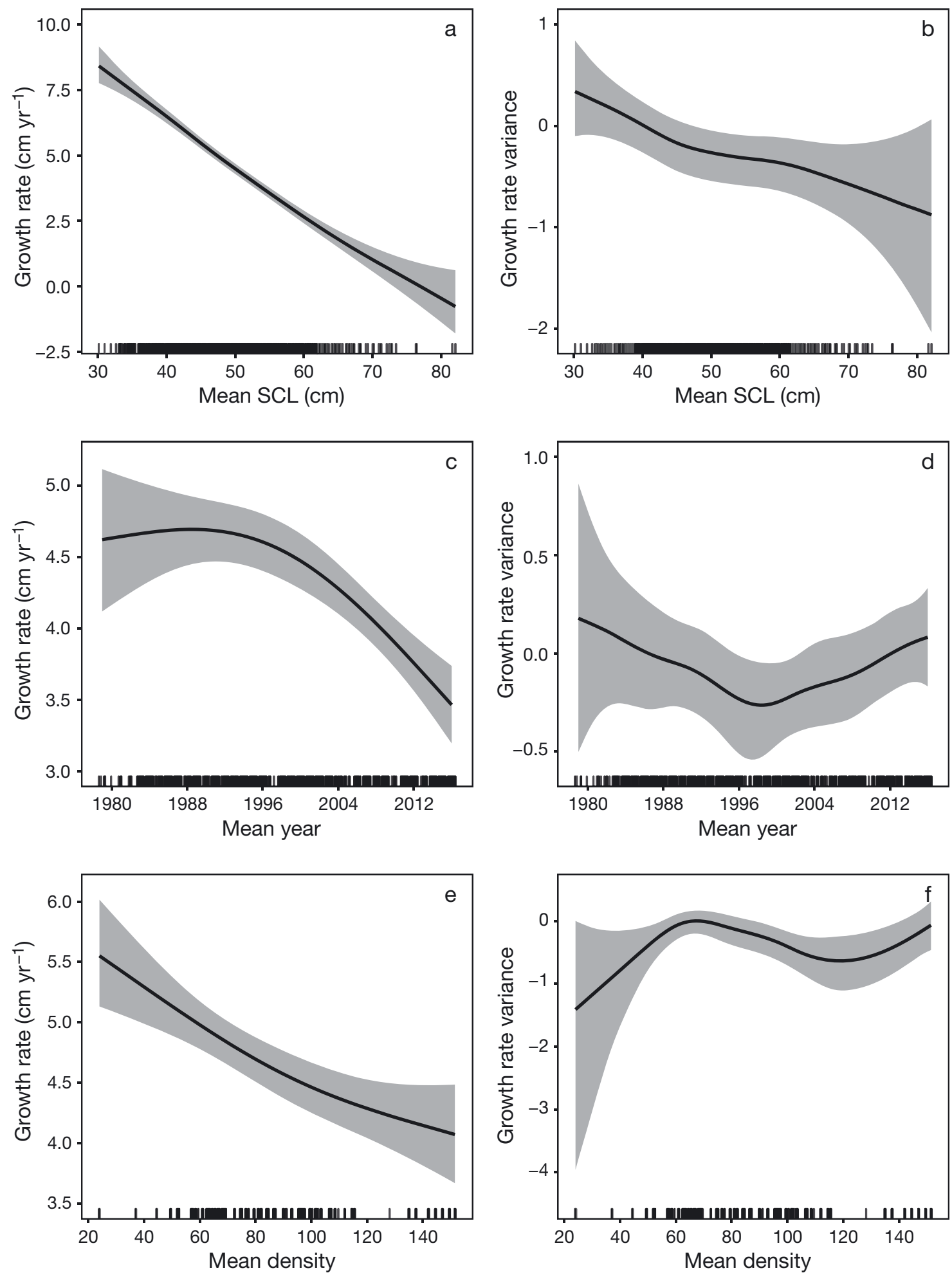

Fig. 2. Distributional regression model analysis (generalized additive mixed model for location, scale and shape; GAMMLSS) for the 3 covariates used as both mean predictors (left side) and variance predictors (right side) for green turtle growth dynamics: $(\mathrm{a}, \mathrm{b})$ mean straight carapace length $(\mathrm{SCL}, \mathrm{cm}) ;(\mathrm{c}, \mathrm{d})$ mean year; $(\mathrm{e}, \mathrm{f})$ mean density (index of relative density). The response variable for the estimated mean effects $(\mathrm{a}, \mathrm{c}, \mathrm{e})$ is mean annual SCL growth rate $\left(\mathrm{cm} \mathrm{yr}^{-1}\right)$; the response variable for the estimated variance effects $(b, d, f)$ is growth rate variance, centered and scaled. Solid curves are the smoothing spline fits conditioned on all other covariates. Shaded areas are bounded by pointwise $95 \%$ credible intervals around the fits. Rug plots indicate distribution of growth increments. All covariates are significant (Bayesian 95\% credible interval does not include zero) 

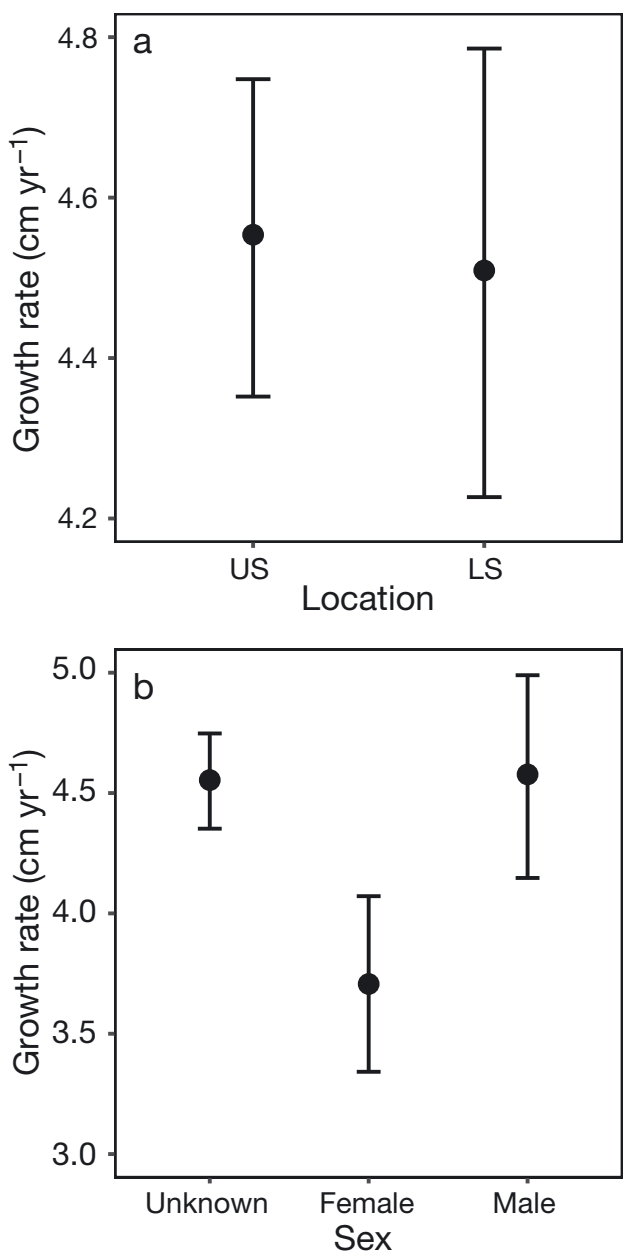

Fig. 3. Distributional regression model analysis (generalized additive mixed model for location, scale and shape; GAMMLSS) for 2 additional mean predictors of green turtle growth dynamics: (a) location of capture in Union Creek Reserve, The Bahamas (US: Upper Sound, $\mathrm{n}=960$ growth increments; LS: Lower Sound, $\mathrm{n}=216$ ) and (b) sex (unknown, $\mathrm{n}=$ 984 growth increments; female, $\mathrm{n}=108$; male, $\mathrm{n}=84$ ). The response variable is mean annual straight carapace length growth rate $\left(\mathrm{cm} \mathrm{yr}^{-1}\right)$. Expected response is shown by closed circles. Bars are $95 \%$ credible intervals around the fits. Differences between females and unknowns and between females and males are significant (Bayesian 95\% credible interval does not include zero)

Based on our model, mean SCL, mean year, and mean density all have significant effects on the mean growth response (Fig. 2a,c,e, Table 1) and the variability in the growth response (Fig. 2b,d,f, Table 1). Duration of growth increments, trimmed to a minimum duration of $330 \mathrm{~d}$, was a significant covariate, but the high degree of uncertainty associated with this parameter does not support confidence in this effect. Location of first capture for each growth increment (Lower Sound vs. Upper Sound; Fig. 3a) did not have a significant effect on growth rates.

\subsection{Sex effect}

Most mark-recapture studies of green turtle aggregations do not identify sex of immature turtles (Bjorndal et al. 2017) and thus cannot assess sex-specific growth. Studies of sex-specific growth in green turtles have reported different results. On the Great Barrier Reef, Australia, green turtles exhibited distinct sex-specific growth patterns, with females growing faster than males from about 62 to $65 \mathrm{~cm}$ curved carapace length (Limpus \& Chaloupka 1997). Goshe et al. (2010) found significant sex-specific growth functions in North Atlantic green turtles, but sex did not have a significant effect on growth of immature green turtles in the northwest Gulf of Mexico (Avens et al. 2012).

Of the 111 turtles sexed in 1988 (65 females and 46 males), 96 were captured more than once and used in our analyses; 7 females and 8 males were only captured once. For sex effects, our model indicates that females ( $\mathrm{n}=108$ growth increments) grow significantly slower than males ( $\mathrm{n}=84$ growth increments) and turtles of unknown sex (Unk; $\mathrm{n}=984$ growth increments). There was no difference between males and Unk turtles (Fig. 3b). This significant difference in mean response contradicts the results of Bolten et al. (1992), who reported no effect of sex on growth rates in this aggregation, but are the same as in Bjorndal et al. (2000). However, Bjorndal et al. (2000) questioned the biological significance of the results for 2 reasons. First, the sample sizes of known-sex turtles were small. Second, if the sex effect is real, growth rates of Unk turtles (a mix of male and female turtles) should fall between those of males and females instead of being equivalent to the males (Fig. 3b). The sex ratio (F:M) of 111 green turtles in UCR was 1.4:1.0 in 1988 (Bolten et al. 1992), the only year in which sex ratio was determined. Thus, the effect of sex on growth rates for the UCR aggregation should be interpreted with caution until additional growth data for turtles of known sex are available.

\subsection{Year effect}

The year effect on growth is a proxy measure of all the environmental influences actually experienced by the green turtles. The mean function of the response distribution over time (Fig. 2c) shows relatively stable growth rates until the late 1990s when growth rates declined consistently until the present. The decline since the late 1990s is similar to the pattern exhibited by green turtles throughout the West 
Atlantic region, which was attributed to an ecological regime shift in the Atlantic influenced largely by the El Niño Southern Oscillation (ENSO) (Bjorndal et al. 2017). Bjorndal et al. (2017) supported this conclusion by calculating annualized mean growth rates generated from their GAMM analysis and reported strong correlations between the annualized mean rates and both sea surface temperatures (SST) and the Multivariate ENSO Index (MEI). We did not repeat those analyses because of our emphasis on exploring the dispersion rather than the mean of the response distribution.

The variance of the response distribution was significant (Table 1, Fig. 2d), indicating that one or more environmental factors varied over the years and affected growth rates either directly or indirectly. Some optimal combination of environmental conditions and green turtle density may have existed in the late 1990s, yielding low variance when all turtles were growing well. Before and after this period, suboptimal conditions may have yielded greater variance in growth rates when turtles exhibited differential capacities to respond to the challenge(s). A greater understanding of effects of environmental conditions on the physiology of sea turtles would greatly improve our ability to interpret variation in growth rates and predict the effects of environmental changes on sea turtle productivity.

\subsection{Body size effect}

The mean response of decreasing growth rates with increasing body size (SCL; Fig. 2a) is clear. Almost all studies of sea turtle growth have reported a significant effect of body size on growth (but see Braun-McNeill et al. 2008), although the shapes of the function vary (Chaloupka \& Musick 1997). In West Atlantic green turtle aggregations, growth functions with increasing body size may be monotonic declining (e.g. Bjorndal et al. 2000, Patrício et al. 2014) or nonmonotonic with highest growth rates at relatively small sizes around $35 \mathrm{~cm}$ SCL (e.g. Kubis et al. 2009) or at larger sizes around 50 to $55 \mathrm{~cm} \mathrm{SCL}$ (e.g. Kubis et al. 2009, Colman et al. 2015).

Importantly, we found that the variance also decreased with increasing body size (Fig. 2b). We predict that variance declines with body size because turtles that emigrate from UCR at smaller sizes are not evenly distributed along the growth rate continuum. That is, turtles that grow at faster (or slower) rates may tend to emigrate at smaller sizes, substantially reducing the variance in growth rates with increasing size as the faster (or slower) growing turtles are disproportionately removed from the aggregation. We compared growth rates of turtles that left UCR at departure sizes less than and greater than the mean departure size ( $55 \mathrm{~cm}$; Fig. S3): 46 to $55 \mathrm{~cm} \mathrm{SCL}$ ( $\mathrm{n}=434)$ and 56 to $65 \mathrm{~cm} \mathrm{SCL}(\mathrm{n}=233)$, respectively. For a fair comparison between these 2 groups, we used growth increments over the same range of mean SCL (31 to $54 \mathrm{~cm} \mathrm{SCL)} \mathrm{with} \mathrm{similar} \mathrm{ranges} \mathrm{of}$ years and relative densities because these 3 parameters had significant effects on growth in our model.

Between 31 and $54 \mathrm{~cm} \mathrm{SCL}$, turtles that left UCR at smaller sizes (46 to $55 \mathrm{~cm} \mathrm{SCL)} \mathrm{grew} \mathrm{significantly}$ slower (growth rate mean $\pm \mathrm{SD}=4.9 \pm 1.9 \mathrm{~cm} \mathrm{yr}^{-1}$ ) than turtles that left at larger sizes (56 to $65 \mathrm{~cm} \mathrm{SCL}$; $5.3 \pm 1.6 \mathrm{~cm} \mathrm{yr}^{-1}$; for statistical results see Table 2). The tendency for slower growing turtles to emigrate at smaller sizes may result from turtles having the ability to recognize and respond to a measure of instantaneous nutritional well-being (Broekhuizen et al. 1994, Roark et al. 2009). Those individuals that recognize their poor nutritional state may leave to seek better foraging habitats. This differential emigration contributes to the decline in variance in growth rates with increasing body size.

\subsection{Density effect}

The mean response was a consistent decline in growth rates with increasing density index (Fig. 2e), probably due to increased competition for food resources. Evidence for density-dependent effects on growth rates has been presented for this aggregation in an earlier study (Bjorndal et al. 2000). Density is a significant driver that underscores the importance of taking into account density-dependent effects on demographic parameters as sea turtle populations recover and population densities increase (Heppell et al. 2003, NRC 2010).

The variance response function (Fig. 2f) suggests lower variance at lower densities (20 to 50), but the credible interval is wide at low densities because of the small sample size, as indicated by the rug plot in Fig. 2f. Thus, the function is not well determined at low densities and requires cautious interpretation.

The $95 \%$ credible or uncertainty interval is narrower from 57 to 110 , the densities over which sample size is consistently high. The steady decline in variance from the peak value at a density index of 66 to 110 is well supported, but somewhat surprising. One might expect that variance would continue to increase with increasing densities as turtles would 
have variable abilities to respond to greater competitive pressure.

We had 2 predictions for the cause of this decline. First, because larger turtles sometimes exclude smaller turtles from limited resources such as resting areas (Thomson et al. 2015), we expected that variance in growth rates of smaller turtles would decrease with increasing density as they are forced into a narrower range of sub-optimal habitats and that variance of larger turtles would not change significantly. Our second prediction was that the decline in variance is a result of differential emigration in larger turtles. We expected that the larger turtles with lower competitive capacity and thus lower growth rates would tend to emigrate sooner, decreasing the variance among larger turtles. To support this contention, variance for larger turtles would need to decrease and mean growth rates for larger turtles would need to stay the same, or at least not decline as much as the entire aggregation (Fig. 2e).

To test these 2 predictions, we compared the means and variances in growth rates of small turtles below the mean of $50 \mathrm{~cm}$ ( 30 to $50 \mathrm{~cm} \mathrm{SCL)} \mathrm{and} \mathrm{large}$ turtles (51 to $73 \mathrm{~cm} \mathrm{SCL}$ ) at low (57 to 70 ) and high (93 to 110) relative densities. For small turtles at low and high densities, the variances remained the same (Table 2). For large turtles at low and high densities, the mean growth rates remained the same and the variances declined at high densities (Table 2).

Therefore, our first prediction, that competition with larger turtles reduces the variance of smaller turtles at higher densities is not supported because variance of smaller turtles remained the same. Although competition does not seem to be a major driver in this instance, better understanding of competition among foraging sea turtles would improve our understanding of the interactions of emigration, turtle density, and habitat quality. The extent to which competition results from differential foraging efficiency among individual turtles as seagrass meadows are more heavily grazed, or to larger or more dominant turtles forcing smaller or less dominant turtles into lower quality habitats should be evaluated. This distinction would provide insights into the behavioral mechanisms driving competition and thus changes in demographic parameters and movement patterns.

Our second prediction - that the decline in variance is a result of earlier emigration in slow-growing larger turtles -is supported. As slow-growing turtles differentially emigrated earlier from the large size class, the variance decreased but the mean growth rates did not, despite the overall decrease in mean growth rates at higher densities (Fig. 2e). The overall decrease in mean growth rates at higher densities is primarily the result of decreased growth rates in smaller turtles ( $t$-test, $t=3.204, \mathrm{df}=329, \mathrm{p}=0.002)$.

\subsection{Differential emigration}

Differential emigration is an important driver of somatic growth dynamics of green turtles in UCR. We found that the decline in variance of growth rates with increasing body size was a result, at least in part, of slower growing turtles emigrating at smaller body sizes than faster growing turtles. We also found the decline in variance of growth rates with increasing density index from 66 to 110 was caused, at least in part, by slower growing larger turtles emigrating sooner than faster growing turtles. Both of these findings support the hypothesis proposed by Werner \& Gilliam (1984) in their review of the theoretical basis for ontogenetic habitat shifts - that a species will shift habitats to maximize growth rates. This slowing of somatic growth rates has been suggested as a cue used by immature loggerheads Caretta caretta to shift from oceanic to neritic habitats (Bolten 2003).

The effects of differential emigration were only revealed in our study through the distributional regression approach that models the dispersion as well as the mean of the response distribution. The importance of differential emigration has not been recognized because earlier studies of growth dynamics evaluated only the mean growth rate response. Differential emigration may well be important for growth dynamics in other sea turtle aggregations and for other demographic parameters, such as survival and sex ratios. Similar studies of growth dynamics in other sea turtle aggregations would be valuable.

Our new insights into differential emigration and the departure of green turtles from foraging grounds are important for understanding sustainability of grazing by green turtles on seagrass meadows, which has become a critical issue (Lal et al. 2010, Kelkar et al. 2013, Heithaus et al. 2014, Molina Hernández \& van Tussenbroek 2014). Green turtles appear to be slow to leave foraging areas in response to declines in seagrass biomass and productivity (Williams 1988, Bjorndal et al. 2000, Lacey et al. 2014), which may result in overgrazing of seagrass meadows (Fourqurean et al. 2010, Christianen et al. 2014). Identification of the cues that stimulate green turtles to leave grazing areas is therefore central to the management of green turtle populations that are 
recovering in many areas (Chaloupka et al. 2008, Mazaris et al. 2017), and to the management of seagrass ecosystems that are in serious decline globally because of anthropogenic threats (Orth et al. 2006, Waycott et al. 2009, Grech et al. 2012).

Greater use of distributional regression modeling approaches in studies of sea turtle growth are important to extend our findings and reveal other drivers. More research is needed to understand the interactions between emigration and parameters, such as nutritional status, body condition, growth rates, and initiation of puberty (sensu Meylan et al. 2011), during developmental migrations as well as the interactions between environmental conditions and sea turtle growth.

Acknowledgements. The long-term study at UCR would not have been possible without the assistance of the Bahamas National Trust (BNT) and BNT wardens on Great Inagua: H. Nixon, R. Burrows, J. Nixon, S. Nixon, and T. Major. We are grateful to the Bahamas Department of Marine Resources for their support and permits to conduct research in The Bahamas. The research was funded by the Disney Conservation Fund and US National Marine Fisheries Service. Morton Bahamas, the US Coast Guard Airstation Clearwater, and the people of Mathew Town, Inagua, provided invaluable logistic support. We thank L. Gape and P. Eliazar for their assistance, and C. Campbell for assistance with the figures. The manuscript benefited from constructive reviews by G. Hays and 2 anonymous reviewers. Publication of this article was funded in part by the University of Florida Open Access Publishing Fund.

\section{LITERATURE CITED}

Avens L, Snover ML (2013) Age and age estimation in sea turtles. In: Wyneken J, Lohmann KJ, Musick JA (eds) The biology of sea turtles, Vol 3. CRC Press, Boca Raton, FL, p 97-133

Avens L, Goshe L, Harms C, Harms CA and others (2012) Population characteristics, age structure, and growth dynamics of neritic juvenile green turtles in the northeastern Gulf of Mexico. Mar Ecol Prog Ser 458:213-229

Balazs G, Chaloupka M (2004) Spatial and temporal variability in somatic growth of green sea turtles resident within the Hawaiian Archipelago. Mar Biol 145:1043-1059

Bjorndal KA (1997) Foraging ecology and nutrition of sea turtles. In: Lutz PL, Musick JA (eds) The biology of sea turtles. CRC Press, Boca Raton, FL, p 199-231

Bjorndal KA, Bolten AB (1988) Growth rates of immature green turtles, Chelonia mydas, on feeding grounds in the southern Bahamas. Copeia 1988:555-564

Bjorndal KA, Bolten AB (2008) Annual variation in source contributions to a mixed stock: implications for quantifying connectivity. Mol Ecol 17:2185-2193

Bjorndal KA, Bolten AB, Chaloupka MY (2000) Green turtle somatic growth model: evidence for density dependence. Ecol Appl 10:269-282

*Bjorndal KA, Bolten AB, Chaloupka MY (2003) Survival probability estimates for immature green turtles, Chelonia mydas, in the Bahamas. Mar Ecol Prog Ser 252:273-281
Bjorndal KA, Bolten AB, Chaloupka MY (2005) Evaluating trends in abundance of immature green turtles, Chelonia mydas, in the Greater Caribbean. Ecol Appl 15:304-314

* Bjorndal KA, Bolten AB, Chaloupka M, Saba VS and others (2017) Ecological regime shift drives declining growth rates of sea turtles throughout the West Atlantic. Glob Change Biol 23:4556-4568

Bolten AB (1999) Techniques for measuring sea turtles. In: Eckert KL, Bjorndal KA, Abreu Grobois FA, Donnelly M (eds) Management and research techniques for the conservation of sea turtles. IUCN, Gland, p 110-114

Bolten AB (2003) Active swimmers-passive drifters: the oceanic juvenile stage of loggerheads in the Atlantic system. In Bolten $\mathrm{AB}$, Witherington $\mathrm{BE}$ (eds) Loggerhead sea turtles. Smithsonian Institution Press, Washington, DC, p 63-78

Bolten AB, Bjorndal KA, Grumbles JS, Owens DW (1992) Sex ratio and sex-specific growth rates in immature green turtles, Chelonia mydas, in the southern Bahamas. Copeia 1992:1098-1103

Braun-McNeill J, Epperly SP, Avens L, Snover ML, Taylor JC (2008) Growth rates of loggerhead sea turtles (Caretta caretta) from the western North Atlantic. Herpetol Conserv Biol 3:273-281

* Broekhuizen N, Gurney WSC, Jones A, Bryant AD (1994) Modelling compensatory growth. Funct Ecol 8:770-782

* Bürkner P (2017) brms: an R package for Bayesian multilevel models using Stan. J Stat Softw 80:1-28

Campbell RD, Nouvellet PE, Newman C, Macdonald DW, Rosell F (2012) The influence of mean climate trends and climate variance on beaver survival and recruitment dynamics. Glob Change Biol 18:2730-2742

* Carpenter B, Gelman A, Hoffman M, Lee D and others (2017) Stan: a probabilistic programming language. J Stat Softw 76:1-32

Chaloupka M, Balazs G (2005) Modelling the effect of fibropapilloma disease on the somatic growth dynamics of Hawaiian green sea turtles. Mar Biol 147:1251-1260

Chaloupka MY, Limpus CJ (1997) Robust statistical modeling of hawksbill sea turtle growth rates (southern Great Barrier Reef). Mar Ecol Prog Ser 146:1-8

Chaloupka MY, Musick JA (1997) Age, growth and population dynamics. In: Lutz P, Musick J (eds) The biology of sea turtles. CRC Press, Boca Raton, FL, p 233-276

* Chaloupka M, Bjorndal KA, Balazs GH, Bolten AB and others (2008) Encouraging outlook for recovery of a once severely exploited marine megaherbivore. Glob Ecol Biogeogr 17:297-304

* Christianen MJA, Herman PMJ, Bouma TJ, Lamers LPM and others (2014) Habitat collapse due to overgrazing threatens turtle conservation in marine protected areas. Proc Biol Sci 281:20132890

* Colman MO, Patrício ARC, McGowan A, Santos AJB and others (2015) Long-term growth and survival dynamics of green turtles (Chelonia mydas) at an isolated tropical archipelago in Brazil. Mar Biol 162:111-122

*DeCarlo TM, Cohen AL, Barkley HC, Cobban Q and others (2015) Coral macrobioerosion is accelerated by ocean acidification and nutrients. Geology 43:7-10

*Fourqurean JW, Manuel S, Coates KA, Kenworthy WJ, Smith SR (2010) Effects of excluding sea turtle herbivores from a seagrass bed: Overgrazing may have led to loss of seagrass meadows in Bermuda. Mar Ecol Prog Ser 419:223-232

*Gabry J (2016) bayesplot: plotting for Bayesian models. R package version 1.1.0. https://CRAN.R-project.org/ package $=$ bayesplot 
Gabry J, Simpson D, Vehtari A, Betancourt M, Gelman A (2019) Visualization in Bayesian workflow. J R Stat Soc [Ser A] 182:389-402

Gelman A, Hill J (2007) Data analysis using regression and multilevel/hierarchical models. Cambridge University Press, New York, NY

*Gelman A, Jakulin A, Pittau M, Su Y (2008) A weakly informative default prior distribution for logistic and other regression models. Ann Appl Stat 2:1360-1383

Gelman A, Hwang J, Vehtari A (2014) Understanding predictive information criteria for Bayesian models. Stat Comput 24:997-1016

*Gelman A, Goodrich B, Gabry J, Ali I (2017) R-squared for Bayesian regression models. https://github.com/jgabry/ bayes_R2/blob/master/bayes_R2.pdf

* Gilman E, Chaloupka M, Peschon J, Ellgen S (2016) Risk factors for seabird bycatch in a pelagic longline tuna fishery. PLOS ONE 11:e0155477

Goshe LR, Avens L, Scharf FS, Southwood AL (2010) Estimation of age at maturation and growth of Atlantic green turtles (Chelonia mydas) using skeletochronology. Mar Biol 157:1725-1740

* Grech A, Chartrand-Miller K, Erftemeijer P, Fonseca M and others (2012) A comparison of threats, vulnerabilities and management approaches in global seagrass bioregions. Environ Res Lett 7:024006

Heithaus MR, Alcoverro T, Arthur R, Burkholder DA and others (2014) Seagrasses in the age of sea turtle conservation and shark overfishing. Front Mar Sci 1:28

Heppell SS, Snover ML, Crowder LB (2003) Sea turtle population ecology. In: Lutz PL, Musick JA, Wyneken J (eds) The biology of sea turtles, Vol 2. CRC Press, Boca Raton, FL, p 275-306

Kelkar N, Arthur R, Marba N, Alcoverro T (2013) Green turtle herbivory dominates the fate of seagrass primary production in the Lakshadweep islands (Indian Ocean). Mar Ecol Prog Ser 485:235-243

Klein N, Kneib T, Lang S, Sohn A (2015) Bayesian structured additive distributional regression with an application to regional income inequality in Germany. Ann Appl Stat 9:1024-1052

Kneib T (2013) Beyond mean regression. Stat Model 13: 275-303

Kubis S, Chaloupka M, Ehrhart L, Bresette M (2009) Growth rates of juvenile green turtles Chelonia mydas from three ecologically distinct foraging habitats along the east central coast of Florida, USA. Mar Ecol Prog Ser 389: 257-269

Lacey EA, Collado-Vides L, Fourqurean JW (2014) Morphological and physiological responses of seagrasses (Alismatales) to grazers (Testudines: Cheloniidae) and the role of these responses as grazing patch abandonment cues. Rev Biol Trop 62:1535-1548

Lal A, Arthur R, Marba N, Lill AWT, Alcoverro T (2010) Implications of conserving an ecosystem modifier: increasing green turtle (Chelonia mydas) densities substantially alters seagrass meadows. Biol Conserv 143: 2730-2738

Limpus C, Chaloupka M (1997) Nonparametric regression modelling of green sea turtle growth rates (southern Great Barrier Reef). Mar Ecol Prog Ser 149:23-34

Mazaris AD, Schofield G, Gkazinou C, Almpanidou V, Hays GC (2017) Global sea turtle conservation successes. Sci Adv 3:e1600730

Meylan PA, Meylan AB, Gray JA (2011) The ecology and migrations of sea turtles 8. Tests of the developmental habitat hypothesis. Bull Am Mus Nat Hist 357:1-70
Molina Hernández AL, van Tussenbroek BI (2014) Patch dynamics and species shifts in seagrass communities under moderate and high grazing pressure by green sea turtles. Mar Ecol Prog Ser 517:143-157

Musick JA, Limpus CJ (1997) Habitat utilization and migration in juvenile sea turtles. In: Lutz PL, Musick JA (eds) The biology of sea turtles. CRC Press, Boca Raton, FL, p 137-163

National Research Council (2010) Assessment of sea-turtle status and trends: integrating demography and abundance. National Academies Press, Washington, DC

Orth RJ, Carruthers TJB, Dennison WC, Duarte CM and others (2006) A global crisis for seagrass ecosystems. Bioscience 56:987-996

* Park T, Casella G (2008) The Bayesian lasso. J Am Stat Assoc 103:681-686

*Patrício R, Diez C, van Dam RP (2014) Spatial and temporal variability of immature green turtle abundance and somatic growth in Puerto Rico. Endang Species Res 23: $51-62$

R Core Team (2017) R: a language and environment for statistical computing. R Foundation for Statistical Computing, Vienna

Roark AM, Bjorndal KA, Bolten AB (2009) Compensatory responses to food restriction in juvenile green turtles (Chelonia mydas). Ecology 90:2524-2534

Silbersdorff A, Lynch J, Klasen S, Kneib T (2018) Reconsidering the income-health relationship using distributional regression. Health Econ 27:1074-1088

* Stan Development Team (2016) The Stan C++ library, version 2.10.0. http://mc-stan.org/

* Stasinopoulos D, Rigby R (2007) Generalized additive models for location scale and shape (GAMLSS) in R. J Stat Softw 23:1-46

Stasinopoulos MD, Rigby RA, De Bastiani F (2018) GAMLSS: a distributional regression approach. Stat Model 18: 248-273

*Thomson JS, Gulick A, Heithaus MR (2015) Intraspecific behavioral dynamics in a green turtle Chelonia mydas foraging aggregation. Mar Ecol Prog Ser 532: 243-256

Trotter MV, Krishna-Kumar S, Tuljapurkar S (2013) Beyond the mean: sensitivities of the variance of population growth. Methods Ecol Evol 4:290-298

*Vehtari A, Gelman A, Gabry J (2017) Practical Bayesian model evaluation using leave-one-out cross-validation and WAIC. Stat Comput 27:1413-1432

Violle C, Enquist BJ, McGill BJ, Jiang L and others (2012) The return of the variance: intraspecific variability in community ecology. Trends Ecol Evol 27:244-252

* Waycott M, Duarte CM, Carruthers TJB, Orth RJ and others (2009) Accelerating loss of seagrasses across the globe threatens coastal ecosystems. Proc Natl Acad Sci USA 106:12377-12381

Werner EE, Gilliam JF (1984) The ontogenetic niche and species interactions in size-structured populations. Annu Rev Ecol Evol Syst 15:393-425

Wickham H (2016) ggplot2: elegant graphics for data analysis, $2^{\text {nd }}$ edn. Springer-Verlag, New York, NY

*Williams SL (1988) Thalassia testudinum productivity and grazing by green turtles in a highly disturbed seagrass bed. Mar Biol 98:447-455

Wood S (2006) Generalized additive models: an introduction with R. CRC Press, Boca Raton, FL

*Wood S, Scheipl F (2014) gamm4: generalized additive mixed models using mgcv and lme4. $\mathrm{R}$ package version 0.2-3. http://CRAN.R-project.org/package=gamm4 